\title{
A conversation with Marc Feldmann
}

S ir Marc Feldmann's research over the last 30 years has focused on the understanding of autoimmune disease, specifically the treatment of rheumatoid arthritis (RA). Feldmann (Figure 1), now at the Kennedy Institute of Rheumatology at Oxford University, championed the importance of antigen presentation and cytokines in autoimmunity, a concept that led to TNF- $\alpha$ blockade. This idea was considered heretical in the 1980s until he and Sir Ravinder Maini led clinical trials showing that blocking TNF- $\alpha$ effectively treated rheumatoid arthritis refractory to previous therapy. TNF- $\alpha$ antibodies Remicade, Humira, and Enbrel are now the cornerstone of a $\$ 25$ billion industry. Many more stories about getting pharma to speed delivery to patients and the power of persistence can be seen on the JCI website, http://www.jci. org/kiosk/cgm.

JCI: Where and how did you grow up?

Feldmann: I was born on the RussianPolish border. My father, an accountant, was lucky enough to be able to take his family out of there at the end of the war and we went to France where his sister had arranged the necessary formalities, but life in France in the immediate postwar era was difficult. He had two cousins - both doctors - one in New Haven, one in Melbourne. They both filled out immigration papers for him and the Australian ones came first, so off we went to Melbourne.

My father's cousin that had sponsored our immigration was quite a charismatic and entertaining person and he made medicine into a very glamorous career. My brother and I decided that was more interesting than accountancy, and so we went to study medicine at the University of Melbourne. The teaching was good, the students encouraged. I got married while I was a student; so it was a good time.

The University hospital I chose in order to learn clinical medicine more quickly, St. Vincent's, had far few clinical students and was in the Irish part of Melbourne. Half the patients had serious alcoholic problems. I make a joke at times that I owe my research career to alcohol. I chose, though, to do research to understand medicine in greater detail and uncover new treatment approaches, which seemed to me to be more interesting than seeing a lot of alcoholic patients with insoluble problems, day after day.
JCI: How did you stumble into doing your research with someone [Gustav Nossal] who was famous for antibody formation and immune tolerance?

Feldmann: I decided, at the end of the first year's hospital work, to do some research. Visiting the Walter and Eliza Hall Institute, I realized it was quite different from other university departments. In about 30 minutes, it became pretty clear that it was where I wanted to go. I didn't know until many years later that I had applied far too late and that they had already chosen their four PhD students. There were five research units, but that year only four students were accepted because Gus Nossal was going on a sabbatical to Paris. I turned

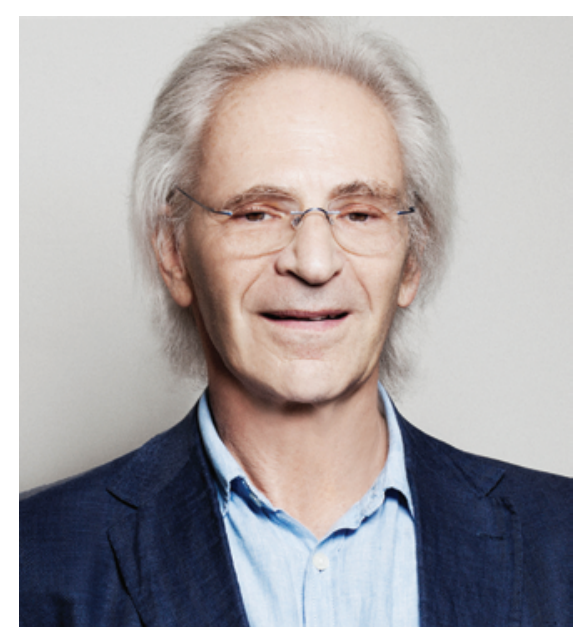

Figure 1

Marc Feldmann on May 20, 2013. Image credit: Alena Soboleva.

up in February, totally unknowing that Gus had shown judgment to take an extra student, and thus launched me on a potential research career. The focus of my $\mathrm{PhD}$ was to improve the generation of immune responses in vitro, to grow cells from the spleen of mice in conditions enabling them to mimic immune responses in vivo. I studied cell interactions, immune regulation and mediators, and learnt from and collaborated with many senior scientists.

JCI: After your PhD, you then decamped back to Europe to do postdoctoral research at the Imperial Cancer Research Fund.

Feldmann: While I was a PhD student, I had another piece of good luck. The Insti- tute went into a financial crisis. Gus had to remain to resolve it, and he sent me to a number of conferences where he had been invited, and they were wonderful, because as a young student I met many of the immunological stars of the time. I met Av Mitchison, a very charismatic scientist to this day. I decided to work with him, continuing to work on cell interactions and to try and characterize some of the mediators that acted as signals from one cell to another.

After years of working with mice, my medical training encouraged me towards a major challenge, tumor immunology, and I started to look at immunity in human cancer patients. It was absolutely impossible to measure any immune responses to cancer. And so, I made the conclusion that what is needed for cancer is to develop an autoimmune disease, to get the immune system to target the cancer. Thus a reasonable next step was to try and understand mechanisms of autoimmunity, a topic of interest discovered by [Frank] Macfarlane Burnet, Gus Nossal's Nobel Prize winning predecessor.

JCI: So, you started working on autoimmunity?

Feldmann: In 1982, a couple of papers had come out looking at the role of HLA antigens and their upregulation in sites of autoimmune diseases, one from Deborah Doniach and Franco Bottazzo at Middlesex Hospital. They came to visit me one day to ask what I thought of the upregulated HLA class II in a diseased tissue, like Graves' disease thyroid. I started to think and realized that this observation was actually a missing link - I developed an idea of how autoimmune diseases were triggered and were sustained through the upregulation of antigen presenting function.

I wrote a hypothetical paper about this, which was published in The Lancet in '83, and despite its age, it's not an embarrassing read. It outlined a link to understanding autoimmunity and cell interactions with some of the key molecules. Once autoimmunity and upregulated antigen presentation were linked, then many other things follow. What upregulates antigen presenting molecules? At the time, the only known signals were cytokines and so I focused on studying cytokines in autoimmunity.

JCI: I imagine this must have been part of what drove you to look at the joint after an initial focus on autoimmune thyroiditis? 
Feldmann: The reason we had originally been interested in thyroid disease was because it was possible to get abundant human diseased cells for research. However, critical for scientific research is funding. Because current therapy of thyroid disease is actually pretty good, there's no incentive to improve it. I considered what other disease had many of the local features and had reasonable amounts of disease tissue available for study in detail. Rheumatoid arthritis seemed to be a logical disease that could be studied with the same technology.

JCI: Not to mention that it occurs in approximately $1 \%$ of the worldwide population, and therefore, would be a bigger market.

Feldmann: Exactly. It was much easier to get grants, and when I expressed an interest in rheumatoid arthritis, I met my long-term colleague, Ravinder, better known as "Tiny Maini." He is a scientifically educated rheumatologist and had been also interested in mediators from lymphoid cells during his lab phase at the Kennedy Institute.

We started by trying to obtain as much human diseased joint tissue as possible, to try to establish the important rate limiting cytokines. We started to "fish" in the cytokine pond before others suspected that it might be very important. At the time people were very interested in cytokines as cancer therapeutics, not as potential drivers of autoimmune diseases, which was why my ideas were considered heretical, and some companies refused to help us by giving us reagents.

JCI: And yet, you persisted and hit upon using TNF- $\alpha$ blockade.

Feldmann: We persisted because we just couldn't believe that these very potent molecules, present in such abnormal quantities with prolonged production kinetics, could just be a byproduct of disease. Helped by skills from my $\mathrm{PhD}$ days, we developed methods to culture synovium, and then my postdoc, Fionula Brennan, was able to do a pivotal experiment, which was to put TNF- $\alpha$ antibodies into a mixed synovial culture and show that production of IL-1 and lots of other inflammatory cytokines were down regulated by the neutralization of TNF. That was the first clue that TNF was the long sought therapeutic target.

JCI: This quickly took off such that in 1992 you and Maini started your first open label, non-blinded trial in 20 RA patients that were otherwise refractory to other treatments.

Feldmann: The excitement was palpable, but there were hurdles, one of which was that our idea of TNF blockade downregulating other cytokines was not well accepted. The popular concept was that autoimmune diseases were driven by CD4 T cells, and thus many companies were starting to work trying to cure RA with anti-CD4 monoclonal antibodies. As we tried to get support to test our idea, we quickly found that they weren't interested in anti-TNF for treating rheumatoid arthritis, even if they had already made anti-TNF monoclonals for treating sepsis following Tony Cerami's interesting work.

JCI: But in this case, your former student, Jim Woody, was at Centocor?

Feldmann: That was very, very fortunate because, although Centocor was also preoccupied with antibodies to CD4, Jim was senior enough that he was able to help us do an anti-TNF clinical trial. We were very fortunate because we had tried to get antiTNF antibodies from companies in the UK and we talked and we talked and we talked, and they all thought it was too dangerous, and too unlikely to work.

JCI: You had stunning success once you started your clinical trials.

Feldmann: We wanted to do a formal clinical trial right from the beginning, with placebo controls, but it turned out that the perception that blocking a host defense molecule like TNF was dangerous was too ingrained to enable us to go straight to a placebo controlled trial. We could not convince anybody that since anti-TNF had been used in several thousand patients that already had severe infection with bacterial sepsis, it could be given safely to people without infection.

It only took about three hours for us to realize that something was happening after infusion of infliximab. It was given slowly, over 3 hours to avoid infusion reactions, but as the first patients were getting it, they told us they were starting to feel better, less tired, and so we had a clue within a few hours of starting.

What we had accomplished in round one was to show that TNF was a good therapeutic target. There was a good clinical effect but it wasn't durable with a single course of treatment. The question was whether any complicated multigenic disease involving many different cells could be eradicated with a single targeted therapeutic, and I think all physicians know the answer: serious diseases like HIV and cancer are treated by polypharmacy.

For immunologists, the simplest thing was just to go back to first principles "What drives immune responses? T cells." And to start asking, "What might happen if T cells were blocked?" With Richard Wil- liams, we used anti-CD4, CTLA4-Ig, and cyclosporine, and all of them gave a very marked prolongation of the benefit of antiTNF in mouse models. The approach for clinical use where we could not use 2 unapproved drugs was to use small molecules that were approved and, after a number of iterations, we finally decided on methotrexate. It was the second phase of our successful translational research and has made for much more durable therapy. To this day we don't understand exactly how methotrexate works, nor do we understand exactly how this combination works, but we had clues from the very beginning, when a patient that was doing very badly on antiTNF was subsequently given methotrexate and had a very good response.

JCI: You've said you did these clinical trials because you were interested in science, and wanted to treat patients but you've also been lauded with several honors and awards, and including the 2003 Lasker Prize, and in 2010, you were knighted by Queen Elizabeth II.

Feldmann: Yes, that was very gratifying. Before the knighting ceremony, they write to you and ask some interesting questions and one is, "Can you kneel?" And then, "Can you get up?" These are relevant questions considering the average age of people getting a knighthood. It was a very nice ceremony at Buckingham Palace.

Awards in science are useful as a motivational, aspirational tool, and I can tell you it is wonderful to know that you haven't wasted all your allocated time on this planet doing research - to know that it has been useful to society. And you can convince your parents, relatives, and spouse that the effort and time away from family was worthwhile.

JCI: If you weren't wasting your time doing all this work, what vocation do you think you would have chosen otherwise?

Feldmann: I grew up in Australia, a sportsmad culture. I did play a lot of tennis and I enjoyed it. Tennis was a very low-ranking sport in the social hierarchy in Australia; in Melbourne the top is Australian rules football, which makes American football appear tame. But I'm about one foot too small for being good at Australian rules. So instead, I played tennis. But that had an advantage, as I'm $100 \%$ certain that none of my school friends are still playing Australian rules now, but I can still play tennis. But that's not serious. If had I not become a scientist, I would have tried to be an artist.

\section{Ushma S. Neill}

